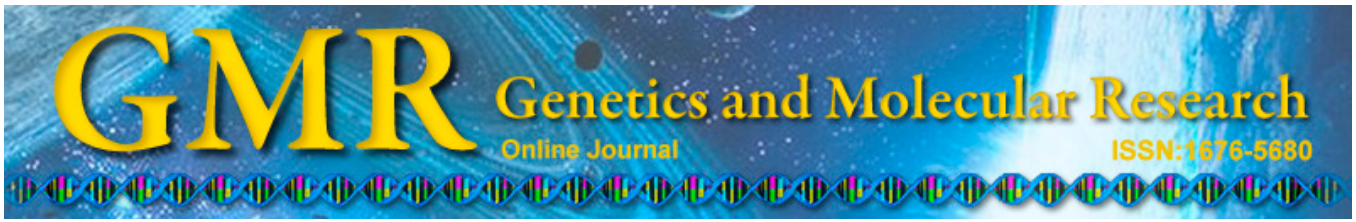

\title{
Resistant starch: a functional food that prevents DNA damage and chemical carcinogenesis
}

\author{
S.D. Navarro ${ }^{1,2,3}$, M.O. Mauro ${ }^{1,3}$, J.R. Pesarini ${ }^{1,4}$, F.M. Ogo ${ }^{5}$ and \\ R.J. Oliveira ${ }^{1,2,4}$ \\ ${ }^{1}$ Centro de Estudos em Células Tronco, \\ Terapia Celular e Genética Toxicológica-CeTroGen, \\ Núcleo de Hospital Universitário, Universidade Federal de Mato Grosso do Sul, \\ Campo Grande, MS, Brasil \\ ${ }^{2}$ Programa de Mestrado em Farmácia, Centro de Ciências Biológicas e da Saúde, \\ Universidade Federal de Mato Grosso do Sul, Campo Grande, MS, Brasil \\ ${ }^{3}$ Programa de Doutorado em Biotecnologia e Biodiversidade-Rede Pró \\ Centro-Oeste, Universidade Federal de Mato Grosso do Sul, \\ Campo Grande, MS, Brasil \\ ${ }^{4}$ Programa de Pós-Graduação em Saúde e Desenvolvimento na Região \\ Centro-Oeste, Faculdade de Medicina "Dr. Hélio Mandetta", \\ Universidade Federal de Mato Grosso do Sul, Campo Grande, MS, Brasil \\ ${ }^{5}$ Centro de Ciências Biológicas, Universidade Estadual de Londrina, \\ Londrina, PR, Brasil \\ Corresponding author: R.J. Oliveira \\ E-mail: rodrigo.oliveira@ufms.br
}

Genet. Mol. Res. 14 (1): 1679-1691 (2015)

Received June 17, 2014

Accepted October 8, 2014

Published March 6, 2015

DOI http://dx.doi.org/10.4238/2015.March.6.14

\begin{abstract}
Resistant starch is formed from starch and its degradation products and is not digested or absorbed in the intestine; thus, it is characterized as a fiber. Because fiber intake is associated with the prevention of DNA damage and cancer, the potential antigenotoxic, antimutagenic, and anticarcinogenic capabilities of resistant starch
\end{abstract}


from green banana flour were evaluated. Animals were treated with 1,2-dimethylhydrazine and their diet was supplemented with $10 \%$ green banana flour according to the following resistant starch protocols: pretreatment, simultaneous treatment, post-treatment, and pre + continuous treatment. The results demonstrated that resistant starch is not genotoxic, mutagenic, or carcinogenic. The results suggest that resistant starch acts through desmutagenesis and bio-antimutagenesis, as well as by reducing aberrant crypt foci, thereby improving disease prognosis. These findings imply that green banana flour has therapeutic properties that should be explored for human dietary applications.

Key words: Green banana; Antigenotoxicity; Antimutagenicity; Anticarcinogenicity; Chemoprevention

\section{INTRODUCTION}

Researchers have reported that inter-individual genetic differences are responsible for varied responses to the environment. Diet, in particular, is a factor that interferes considerably with differential gene expression because genes are exposed to various dietary influences throughout life (Mauro et al., 2011). Intestinal and colorectal cancers are closely related to eating habits and the expression of certain genes. Thus, diet, functional foods, or both, that alter gene expression might correlate with the prevention of such neoplasms (Bergmann et al., 2006). Conversely, according to Chao et al. (2005) and the World Cancer Research Fund (1997), diets that contain high concentrations of protein, including red or processed meats, animal fats, alcohol, and carbohydrates (Stevens et al., 2007), are associated with a high risk of these tumors.

The World Health Organization estimates that approximately 21 million new cases of cancer will occur in 2030 and an estimated 13 million patients will die from cancer (Instituto Nacional do Câncer, 2014). In Brazil, the total number of current cancer cases is approximately 518,510, with colorectal cancer ranking fourth (Instituto Nacional do Câncer, 2012). These data underscore the necessity of understanding the developmental stages of this disease and relating these stages to preventative mechanisms such as consuming food compounds with potential anticancer activities (Mauro et al., 2013). This strategy would be a key alternative for residents of countries with insufficient resources to address this important and annually worsening public health issue.

Nutritional re-education based on a pre- and probiotic-rich diet of healthy foods might help prevent colorectal cancer given the considerable evidence that intestinal bacterial flora are involved in the development of intestinal and colorectal tumors (McBain and MacFarlane, 2001; Burns and Rowland, 2004). Prebiotic foods such as fibers are nondigestible foods that act beneficially by selectively stimulating the growth, activity, or both, of host bacterial flora (McBain and MacFarlane, 2001) to help prevent cancer. These foods are easily accessible, are naturally present in the diet (Roberfroid, 2005), and provide prebiotic resistant starch actions.

The resistant starch present in green banana flour can be classified as a prebiotic food because, according to Asp and Björck (1992), resistant starch is the sum of starches and starch degradation products that are not digested or absorbed in the small intestines of healthy individuals, and therefore, resistant starch is characterized as a fiber. 
The scientific evidence showing that fiber prevents colorectal cancers has increased scientific interest in this food compound. In this study, the potential antigenotoxic, antimutagenic, and anticarcinogenic properties of resistant starch extracted from green bananas were evaluated in an experimental model.

\section{MATERIAL AND METHODS}

\section{1,2-Dimethylhydrazine}

The DNA damage-inducing and cancer-promoting agent 1,2-dimethylhydrazine (DMH, CAS No. 306-37-6; Sigma-Aldrich, St. Louis, MO, USA) was diluted in a $0.37 \mathrm{mg} /$ $\mathrm{mL}$ ethylenediaminetetraacetic acid (EDTA) solution and administered intraperitoneally (ip) to animals following a modified version of the protocol of Rodrigues et al. (2002). DMH was administered in 4 doses of $20 \mathrm{mg} / \mathrm{kg}$ body weight (bw) twice weekly for 2 weeks.

\section{Green banana skin and pulp drying method and flour preparation}

Green banana flour was prepared according to the method described by Juarez-Garcia et al. (2006). Banana samples were prewashed and then immersed in a $50 \mathrm{ppm}$ sodium hypochlorite solution.

The fruits were then cut into approximately $1-\mathrm{cm}$-thick slices that were immediately immersed in a $0.3 \%$ citric acid solution for antioxidation treatment. The fruit slices were then dried in an oven at $50^{\circ} \mathrm{C}$ for $72 \mathrm{~h}$. After drying, the samples were ground into flour, which was stored at $25^{\circ} \mathrm{C}$ in plastic containers for later use.

The green banana flour was added to commercial feed (Nuvital, Curitiba, PR, Brazil) at a $10 \%$ concentration as an animal dietary supplement. This mixture was offered ad libitum to the animals according to the protocols and treatments described in the experimental design.

\section{Animals and experimental design}

A total of 70 male Swiss mice (Mus musculus) of reproductive age were divided into 7 groups $(\mathrm{N}=10$ animals). Animals were housed in propylene boxes lined with wood shavings and fed either commercial or supplemented feed; filtered water was available ad libitum. Temperature and lighting were controlled in a 24-h photoperiod (12 h light: $12 \mathrm{~h}$ dark) at a temperature of $22^{\circ} \pm 2^{\circ} \mathrm{C}$ and $55 \pm 10 \%$ humidity. The experiment was conducted according to the guidelines of the Universal Declaration of Animal Rights and with the approval of the Ethics Committee on Animal Use, Universidade Federal do Mato Grosso do Sul (Protocol No. 454/2012). The animals were treated for 12 weeks according to the protocol proposed by Bolognani et al. (2001) and adapted by Mauro et al. (2013), as follows:

Negative control group: Animals were fed commercial feed ad libitum during the 12-week experimental period. In the third and fourth weeks of experimentation, the animals were treated with 4 doses of EDTA $(0.1 \mathrm{~mL} / 10 \mathrm{~g}$ bw ip $)$. After the last administration, peripheral blood samples were collected from the animals via caudal venipuncture and used for genotoxicity and mutagenicity evaluations. Mutagenicity assessments were performed with a micronucleus assay that was performed at $\mathrm{T} 1, \mathrm{~T} 2$, and $\mathrm{T} 3$, which corresponded to 24,48 , and 
$72 \mathrm{~h}$ after the last vehicle administration. Genotoxicity was assessed with a comet assay only in $\mathrm{T} 1$ samples.

Positive control group (DMH group): Animals were treated similarly to those in the negative control group and underwent the same blood sample collection procedure. However, instead of EDTA, the animals received DMH $(20 \mathrm{mg} / \mathrm{kg}$ bw ip $)$.

Resistant starch group: Animals were fed ad libitum commercial feed supplemented with $10 \%$ green banana flour during the 12 -week experimental period. In the third and fourth weeks of experimentation, the animals were subjected to the treatments described for the negative control group and underwent the same biological sample collections.

Pre-treatment group: Animals received commercial feed supplemented with $10 \%$ green banana flour during the first 2 weeks. From the third until the twelfth weeks, the animals received commercial feed. In the third and fourth weeks of experimentation, the animals were subjected to treatments and biological sample collections described for the positive control group. The protocol for this group involved evaluation of antigenotoxicity (T1) and antimutagenicity (T1, T2, and T3).

Simultaneous group: Animals received DMH (20 mg/kg bw ip) in the third and fourth weeks of experimentation and also received commercial feed supplemented with $10 \%$ green banana flour ad libitum during that two-week period. In the first and second weeks and then from the fifth to the twelfth weeks, the animals were fed commercial feed ad libitum. Biological samples were collected as described above for antigenotoxicity (T1) and antimutagenicity (T1, T2, and T3) evaluations.

Post-treatment group: Animals received DMH ( $20 \mathrm{mg} / \mathrm{kg}$ bw ip $)$ treatment in the third and fourth weeks. The animals were fed with commercial feed during the first 4 weeks and were fed ad libitum with commercial feed supplemented with $10 \%$ green banana flour during the last 8 weeks. Biological samples were collected as described above for antigenotoxicity (T1) and antimutagenicity (T1, T2, and T3) evaluations.

Pre + continuous group: Animals were fed ad libitum diets supplemented with 10\% green banana flour throughout the 12-week experimental period. In the third and fourth weeks, the animals were treated with DMH $(20 \mathrm{mg} / \mathrm{kg}$ bw ip). Biological samples for antigenotoxicity (T1) and antimutagenicity (T1, T2, and T3) evaluations were collected as described above. In the twelfth week of the experiment, the animals from all groups were killed via cervical dislocation and their intestines and colons were collected and tested for aberrant crypt foci.

\section{Comet assay}

Comet assays were performed according to the procedure described by Oliveira et al. (2009) as follows. Peripheral blood $(20 \mu \mathrm{L})$ was collected $(24 \mathrm{~h}$ after the last dose of EDTA or $\mathrm{DMH}$ ) into heparinized cryotubes, homogenized with $120 \mu \mathrm{L} 1.5 \%$ low-melting-point agarose at $37^{\circ} \mathrm{C}$, and placed onto slides coated with standard $5 \%$ agarose. The slides were covered with glass coverslips and cooled to $4^{\circ} \mathrm{C}$ for $20 \mathrm{~min}$. After coverslip removal, the slides from all experiments were immersed in freshly prepared lysis solution composed of $89 \mathrm{~mL}$ stock lysis buffer $(2.5 \mathrm{M} \mathrm{NaCl}, 100 \mathrm{mM}$ EDTA, $10 \mathrm{mM}$ Tris adjusted to $\mathrm{pH} 10$ with solid $\mathrm{NaOH}, 890 \mathrm{~mL}$ distilled water, and 1\% sodium lauroyl sarcosinate), 1 mL Triton X-100 (Merck, Germany), and $10 \mathrm{~mL}$ dimethyl sulfoxide. The samples were lysed for $1 \mathrm{~h}$ at $4^{\circ} \mathrm{C}$ with protection from light.

The slides were then transferred to an electrophoresis tank containing buffer with a $\mathrm{pH}$ of $>13$ (300 mM NaOH and $1 \mathrm{mM}$ EDTA prepared from a stock solution of $200 \mathrm{mM}$ EDTA 
and $10 \mathrm{~N} \mathrm{NaOH}, \mathrm{pH} 10.0$ ) at $4^{\circ} \mathrm{C}$ and incubated for $20 \mathrm{~min}$ for DNA denaturation. Electrophoresis was performed at $300 \mathrm{~mA}$ and $25 \mathrm{~V}(1.25 \mathrm{~V} / \mathrm{cm})$ for $20 \mathrm{~min}$. Subsequently, the slides were neutralized with buffer $(0.4 \mathrm{M}$ Tris- $\mathrm{HCl}, \mathrm{pH} 7.5)$ in 3 cycles of 5 min each, air-dried, fixed in absolute ethanol for $10 \mathrm{~min}$, and stored for later analysis. Next, $100 \mu \mathrm{L}$ ethidium bromide $(20 \mu \mathrm{g} / \mathrm{mL})$ was used for staining. The samples were evaluated at $40 \mathrm{X}$ magnification under a fluorescence microscope (Bioval ${ }^{\mathbb{B}}$ Model G 2000A, Brazil) fitted with a 420- to 490$\mathrm{nm}$ excitation filter and a 520-nm barrier filter.

In total, 100 cells per animal were visually analyzed, and the comets were classified as follows: class 0 , undamaged cells without tails; class 1 , cells with tails smaller than the nucleoid diameter; class 2, cells with tails 1 - to 2-fold the nucleoid diameter; and class 3, cells with tails greater than 2-fold the nucleoid diameter. Apoptotic cells and those with totally fragmented nucleoids were not counted (Kobayashi et al., 1995). The total score was calculated by adding the results from the multiplication of the total number of observed cells per injury class by the class value. Statistical analysis was performed with analysis of variance (ANOVA) and the Tukey test $(\mathrm{P}<0.05)$.

\section{Peripheral blood micronucleus assay}

The micronucleus assay development method described by Hayashi et al. (1990) and modified by Oliveira et al. (2009) was used. Slides were coated with $20 \mu \mathrm{L}$ acridine orange (1 $\mathrm{mg} / \mathrm{mL}$ ). Next, $20 \mu \mathrm{L}$ peripheral blood was deposited onto each slide, covered with a coverslip, and stored in a freezer $\left(-20^{\circ} \mathrm{C}\right)$ for a minimum of 7 days. Analysis was performed at $40 \mathrm{X}$ magnification under an epifluorescence microscope (Bioval ${ }^{\circledR}$, Model L 2000A, Brazil) with a 420- to 490-nm excitation filter and a 520-nm barrier filter. A total of 2000 cells/animal were analyzed, and statistical analysis was performed with ANOVA and the Tukey test $(\mathrm{P}<0.05)$.

\section{Testing of aberrant crypt foci}

The collected mouse colons and rectums were washed in a physiological buffer solution and then dissected for subsequent fixation in $10 \%$ buffered formalin for a minimum of $24 \mathrm{~h}$. For analysis, each colorectal segment was stained with $10 \%$ methylene blue solution for 10 min and placed on a slide mucosal side up. Analysis was performed at 10X magnification using a light microscope. The entire mucosa was evaluated to identify and quantify aberrant crypt foci. Aberrant crypt foci were identified using the criteria described by Bird (1987) and modified by Mauro et al. (2013) as follows. (I) In foci with a single crypt, the aberrant crypt is coated in a thick epithelial layer with an elliptical luminal opening at least 2-fold larger than those of the surrounding normal crypts. (II) In foci with 2 or more crypts, the aberrant crypts form distinct blocks and occupy an area larger than that occupied by an equal number of crypts of normal morphology. In the latter, no normal crypts separate the aberrant crypts in the foci. Comparison of the aberrant crypt foci test data (total number of foci of aberrant crypts, number of aberrant crypts per foci, and crypts/foci ratio) from the experimental groups was performed with ANOVA and the Tukey test $(\mathrm{P}<0.05)$.

\section{Calculation of percent damage reduction}

The percentage of DMH damage reduction by green banana flour compounds in the 
various experiments was calculated as suggested by Manoharan and Banerjee (1985):

$$
\mathrm{DR} \%=\left[\frac{\text { Mean of positive control }- \text { Mean of associated group }}{\text { Mean of positive control }- \text { Mean of negative control }}\right] \times 100
$$

\section{RESULTS}

The initial weights of animals from each experimental group were not significantly different $(\mathrm{P}>0.05)$. However, an analysis of their final weights and weight gains demonstrated that banana flour supplementation in both the resistant starch and pre + continuous treatment groups caused statistically significant reductions $(\mathrm{P}<0.05$; Table 1$)$.

Table 1. Mean \pm standard error of initial/final weight and weight gain during the experimental period.
\begin{tabular}{lccc}
\hline Experimental group & Initial weight $(\mathrm{g})$ & Final weight $(\mathrm{g})$ & Weight gain $(\mathrm{g})$ \\
\hline Control & $34.80 \pm 1.27^{\mathrm{a}}$ & $41.80 \pm 1.59^{\mathrm{a}}$ & $7.00 \pm 1.37^{\mathrm{a}}$ \\
Positive control & $35.40 \pm 1.16^{\mathrm{a}}$ & $39.00 \pm 0.80^{\mathrm{a}, \mathrm{b}}$ & $3.60 \pm 1.32^{\mathrm{a}, \mathrm{b}}$ \\
Resistant starch & $35.80 \pm 0.96^{\mathrm{a}}$ & $34.10 \pm 1.38^{\mathrm{b}, \mathrm{c}}$ & $-1.70 \pm 1.03^{\mathrm{b}, \mathrm{c}}$ \\
Pretreatment & $36.00 \pm 2.35^{\mathrm{a}}$ & $38.00 \pm 1.66^{\mathrm{a}, \mathrm{b}}$ & $2.00 \pm 2.10^{0^{\mathrm{b}, \mathrm{b}, \mathrm{c}}}$ \\
Simultaneous & $35.40 \pm 1.66^{\mathrm{a}}$ & $37.20 \pm 1.37^{\mathrm{a}, \mathrm{b}}$ & $1.80 \pm 2.07^{\mathrm{a}, \mathrm{b}}$ \\
Post-treatment & $36.80 \pm 1.04^{\mathrm{a}}$ & $40.80 \pm 1.27^{\mathrm{a}}$ & $4.00 \pm 1.11^{\mathrm{a}, \mathrm{b}}$ \\
Pre + continuous & $35.80 \pm 1.67^{\mathrm{a}}$ & $30.80 \pm 1.20^{\mathrm{c}}$ & $-5.00 \pm 2.19^{\mathrm{c}}$ \\
\hline
\end{tabular}

Different letters indicate statistically significant differences $(\mathrm{P}<0.05$; analysis of variance/Tukey).

The absolute organ weight analysis revealed that lung weights were not significantly different among the groups. By contrast, the hearts, livers, and kidneys showed significant weight differences $(\mathrm{P}<0.05)$. Nevertheless, no differences were observed in the heart weights relative to the other organ weights. In the DMH group, the lungs and livers had the lower weights $(\mathrm{P}<0.05)$. Kidney weight reductions were observed in the DMH and post-treatment groups $(\mathrm{P}<0.05$; Table 2$)$.

The results of the comet assays indicated that resistant starch supplementation had no genotoxic effects. In the antimutagenicity evaluation, resistant starch effectively reduced the frequency of damaged cells in all treatment groups and therefore demonstrated significant antimutagenic activity $(\mathrm{P}<0.05)$. DNA damage was reduced by $50.71,11.62,77.74$, and $28.34 \%$ in the pretreatment, simultaneous treatment, post-treatment, and pre + continuous treatment groups, respectively (Table 3 ).

The results of the micronucleus assay evaluation revealed that the resistant starchrich diet was not mutagenic and had important antimutagenic activity $(\mathrm{P}<0.05)$ in all tested groups. The damage was reduced by $70.60,100.75,93.23$, and $87.96 \%$ at $\mathrm{T} 1 ; 84.2 \%, 100.00$, 92.56, and $87.60 \%$ at $\mathrm{T} 2$; and $95.55,100.00,86.66$, and $100.00 \%$ at $\mathrm{T} 3$ in the pretreatment, simultaneous treatment, post-treatment, and pre + continuous treatment groups, respectively (Table 4). 
Resistant starch as a chemopreventive agent

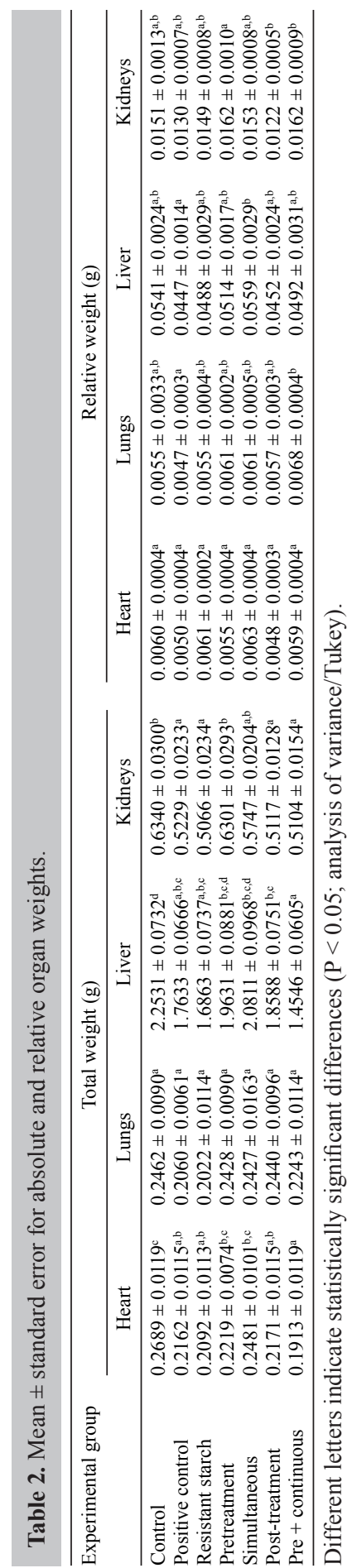


Table 3. Mean \pm standard error, frequency of damaged cells, and distribution between damage classes.

\begin{tabular}{|c|c|c|c|c|c|c|c|}
\hline \multirow[t]{2}{*}{ Experimental group } & \multirow[t]{2}{*}{ Damaged cells } & \multicolumn{4}{|c|}{ Damage class } & \multirow[t]{2}{*}{ Score } & \multirow[t]{2}{*}{ DR\% } \\
\hline & & 0 & 1 & 2 & 3 & & \\
\hline \multicolumn{8}{|l|}{ Genotoxicity } \\
\hline Control & $0.40 \pm 0.22^{\mathrm{a}}$ & $99.60 \pm 0.21$ & $0.40 \pm 0.22$ & $0.00 \pm 0.00$ & $0.00 \pm 0.0$ & $0.40 \pm 0.22^{\mathrm{a}}$ & - \\
\hline Positive control & $92.50 \pm 0.88^{\mathrm{f}}$ & $7.50 \pm 0.88$ & $46.00 \pm 2.74$ & $25.50 \pm 2.28$ & $21.00 \pm 2.26$ & $160.00 \pm 5.25^{\mathrm{f}}$ & - \\
\hline Resistant starch & $0.70 \pm 0.39^{\mathrm{a}}$ & $99.30 \pm 0.39$ & $0.70 \pm 0.39$ & $0.00 \pm 0.00$ & $0.00 \pm 0.00$ & $7.00 \pm 0.70^{\mathrm{a}}$ & - \\
\hline \multicolumn{8}{|l|}{ Antigenotoxicity } \\
\hline Pretreatment & $45.80 \pm 2.52^{\mathrm{c}}$ & $54.20 \pm 2.52$ & $30.80 \pm 1.25$ & $8.90 \pm 0.60$ & $6.10 \pm 0.92$ & $66.90 \pm 4.70^{\mathrm{c}}$ & 50.71 \\
\hline Simultaneous & $81.80 \pm 0.90^{\mathrm{e}}$ & $18.20 \pm 0.90$ & $37.90 \pm 1.35$ & $33.30 \pm 1.46$ & $10.60 \pm 1.48$ & $136.60 \pm 2.18^{\mathrm{e}}$ & 11.62 \\
\hline Post-treatment & $20.90 \pm 1.41^{\mathrm{b}}$ & $79.10 \pm 1.41$ & $10.00 \pm 0.94$ & $6.50 \pm 0.60$ & $4.40 \pm 0.89$ & $36.20 \pm 2.89^{\mathrm{b}}$ & 77.74 \\
\hline Pre + continuous & $66.40 \pm 1.23^{\mathrm{d}}$ & $33.60 \pm 1.23$ & $29.30 \pm 1.35$ & $23.30 \pm 1.16$ & $13.80 \pm 1.16$ & $117.30 \pm 3.14^{\mathrm{d}}$ & 28.34 \\
\hline
\end{tabular}

$\mathrm{DR} \%=$ percent damage reduction. Different letters indicate statistically significant differences $(\mathrm{P}<0.05$; analysis of variance/Tukey).

Table 4. Total frequency and mean $\pm \mathrm{SE}$ of the micronucleus assay in mouse peripheral blood cells.

\begin{tabular}{|c|c|c|c|c|c|c|c|c|c|}
\hline \multirow[t]{2}{*}{ Experimental group } & \multicolumn{3}{|c|}{ Micronucleus frequency } & \multicolumn{3}{|c|}{ Mean \pm SE } & \multicolumn{3}{|c|}{$\mathrm{DR} \%$} \\
\hline & $\mathrm{T} 1$ & $\mathrm{~T} 2$ & $\mathrm{~T} 3$ & $\mathrm{~T} 1$ & $\mathrm{~T} 2$ & $\mathrm{~T} 3$ & $\mathrm{~T} 1$ & $\mathrm{~T} 2$ & $\mathrm{~T} 3$ \\
\hline \multicolumn{10}{|l|}{ Mutagenicity } \\
\hline Control & 63 & 39 & 30 & $6.30 \pm 0.59^{\mathrm{a}, \mathrm{b}, \mathrm{c}}$ & $3.9 \pm 0.64^{\mathrm{a}}$ & $3.0 \pm 0.39^{\mathrm{a}}$ & - & - & - \\
\hline Positive control & 196 & 160 & 75 & $19.60 \pm 0.40^{\mathrm{e}}$ & $16.0 \pm 0.61^{\mathrm{c}}$ & $7.5 \pm 0.42^{\mathrm{b}}$ & - & - & - \\
\hline Resistant starch & 48 & 44 & 35 & $4.80 \pm 0.32^{\mathrm{a}}$ & $4.4 \pm 0.26^{\mathrm{a}, \mathrm{b}}$ & $3.5 \pm 0.26^{\mathrm{a}}$ & - & - & - \\
\hline \multicolumn{10}{|l|}{ Antimutagenicity } \\
\hline Pretreatment & 102 & 58 & 32 & $9.00 \pm 0.25^{\mathrm{d}}$ & $5.8 \pm 0.24^{b}$ & $3.1 \pm 0.27^{\mathrm{a}}$ & 70.6 & 84.29 & 95.55 \\
\hline Simultaneous & 62 & 39 & 30 & $6.20 \pm 0.38^{\mathrm{a}, \mathrm{b}}$ & $3.9 \pm 0.31^{\mathrm{a}}$ & $3.0 \pm 0.25^{\mathrm{a}}$ & 100.75 & 100.00 & 100.00 \\
\hline Post-treatment & 72 & 48 & 36 & $7.20 \pm 0.35^{\mathrm{b}, \mathrm{c}}$ & $4.8 \pm 0.35^{\mathrm{a}, \mathrm{b}}$ & $3.6 \pm 0.30^{\mathrm{a}}$ & 93.23 & 92.56 & 86.66 \\
\hline Pre + continuous & 79 & 54 & 30 & $7.90 \pm 0.23^{\mathrm{c}, \mathrm{d}}$ & $5.4 \pm 0.30^{\mathrm{a}, \mathrm{b}}$ & $3.0 \pm 0.25^{\mathrm{a}}$ & 87.96 & 87.60 & 100.00 \\
\hline
\end{tabular}

$\mathrm{DR} \%=$ percent damage reduction; $\mathrm{SE}=$ standard error. Different letters indicate statistically significant differences $(\mathrm{P}<0.05$; analysis of variance/Tukey).

Table 5 shows that the animals in the control and resistant starch groups showed no aberrant crypt foci in the colorectal mucosa, indicating the absence of any carcinogenic effects due to resistant starch supplementation. However, when this supplementation was administered concurrently with a cancer-inducing agent, it significantly reduced $(\mathrm{P}<0.05)$ the frequency of aberrant crypt foci, a cancer biomarker, in all treatment groups. This chemopreventive activity was evident from the percentages of damage reduction in the intestinal mucosa, which were 62.92, 55.33, 51.12 , and $67.41 \%$ in the pretreatment, simultaneous treatment, post-treatment, and pre + continuous groups, respectively. The lowest crypts/foci ratio was detected in the post-treatment group.

Table 5. Number, distribution, and percent damage reduction (DR\%) of aberrant crypt foci.

\begin{tabular}{|c|c|c|c|c|c|c|c|c|c|}
\hline \multirow[t]{2}{*}{ Experimental group } & \multicolumn{2}{|c|}{ AC foci (total) } & \multirow[t]{2}{*}{$\mathrm{DR} \%$} & \multirow[t]{2}{*}{ AC (total) } & \multicolumn{4}{|c|}{ AV of crypts/foci } & \multirow[t]{2}{*}{$\mathrm{AC} /$ foci ratio } \\
\hline & $\mathrm{AV}$ & Mean \pm SE & & & $1 \mathrm{AC} /$ foci & $2 \mathrm{AC} /$ foci & $3 \mathrm{AC} /$ foci & $4 \mathrm{AC} /$ foci & \\
\hline \multicolumn{10}{|l|}{ Carcinogenicity } \\
\hline Control & 0 & $0^{\mathrm{a}}$ & - & 0.00 & 0.00 & 0.00 & 0.00 & 0.00 & 0.00 \\
\hline Positive control & 356 & $35.6 \pm 0.85^{\mathrm{e}}$ & - & 743 & 108 & 92 & 73 & 58 & 2.08 \\
\hline Resistant starch & 0 & $0^{\mathrm{a}}$ & - & 0.00 & 0.00 & 0.00 & 0.00 & 0.00 & 0.00 \\
\hline \multicolumn{10}{|l|}{ Anticarcinogenicity } \\
\hline Pretreatment & 132 & $13.2 \pm 1.02^{\mathrm{b}}$ & 62.92 & 272 & 43 & 43 & 33 & 11 & 2.06 \\
\hline Simultaneous & 159 & $15.9 \pm 0.69^{d}$ & 55.33 & 341 & 47 & 44 & 30 & 29 & 2.14 \\
\hline Post-treatment & 174 & $17.4 \pm 0.63^{\mathrm{c}, \mathrm{d}}$ & 51.12 & 288 & 68 & 63 & 33 & 7 & 1.65 \\
\hline Pre + continuous & 116 & $11.6 \pm 0.54^{\mathrm{b}}$ & 67.41 & 238 & 38 & 36 & 28 & 11 & 2.05 \\
\hline
\end{tabular}

$\mathrm{AC}=$ aberrant crypts; $\mathrm{AV}=$ absolute values; $\mathrm{SE}=$ standard error. Different letters indicate statistically significant differences $(\mathrm{P}<0.05$; analysis of variance/Tukey). 


\section{DISCUSSION}

Studies suggest that diets containing prebiotics such as resistant starch plays a significant role in preventing colorectal cancer due to the high potential antigenotoxic, antimutagenic, and anticarcinogenic activities of these compounds (Liu and Xu, 2008; Clark et al., 2012). According to Champ and Faisant (1996), resistant starch is the starch fraction that provides no glucose to the body. However, resistant starch is fermented in the large intestine mainly to produce gases and short-chain fatty acids. The activities of resistant starch, as well as the effects observed in this study, are attributable to these characteristics.

Because resistant starch is not digested in the large intestine, it becomes an available substrate for fermentation by anaerobic bacteria present in the colon (Jenkins et al., 1998). Thus, this fraction shares many of the features and benefits attributed to dietary fiber in the gastrointestinal tract and thus might be a food with prebiotic potential (Muir and O'Dea, 1992).

Studies have shown that genotoxicity, mutagenicity, and carcinogenicity are correlated processes in which many chemical carcinogens can interact with genetic materials to cause cancer-inducing mutations (Vogel, 1982; Mauro et al., 2013). DMH acts similarly due to its capacity to cause DNA alkylation. Therefore, the aim of the present study was to evaluate the potential antigenotoxic and antimutagenic effects of resistant starch and relate them to the possible anticarcinogenic activity of this food compound. Resistant starch is inexpensive to acquire and prepare and could therefore be used not only in the diets of the general population, including those that are less financially privileged, but also in the diets of those seriously affected by colorectal cancer, which is an important public health issue in Brazil and worldwide.

The results of the comet assays, which were used to assess the genotoxic and antigenotoxic activities of the dietary supplements, indicated that resistant starch had no genotoxic activity but exhibited antigenotoxic effects in the pretreatment, post-treatment, and pre + continuous treatment groups. The reduced frequency of genotoxicity in these experimental groups likely occurred due to the longer supplement consumption period and therefore to the longer exposure of the lumen to fiber and the consequent improvement in the intestinal epithelium, because fiber has beneficial properties for mucin composition (glycoproteins that protect mucous membranes from environmental aggressions) (Roberfroid, 2005). However, this premise assumes that in the simultaneous treatment group, the intestinal epithelium had insufficient time to improve mucin production, leading to a greater absorption of DMH-derived xenobiotics that in turn increased the frequency of cells with genotoxic damage.

Another hypothesis that might explain the antigenotoxic activity of resistant starch is that it acts as a fiber and increases intestinal transit. Thus, xenobiotics would be in contact with the intestinal mucosa for a shorter period of time. There would also be a shorter amount of time for the intestinal flora to degrade these xenobiotics, reducing the release, absorption, or both, of products with genotoxic, mutagenic, or carcinogenic potential.

Given the antigenotoxic action observed and based on the assumption of a correlation between genotoxic and mutagenic events, we evaluated the mutagenic and antimutagenic activities of resistant starch and determined the relevant frequencies of damage-reducing effects at 3 different experimental times. This reduction was confirmed by the data obtained in the comet assay; specifically, when antigenotoxic activity occurs, a reduction in the frequency of mutagenic damage is expected (Vogel, 1982).

However, this statement was untrue for the simultaneous treatment group because antigenotoxic activity was not observed. However, in the micronucleus test, this treatment group 
showed damage reduction percentages of $93.23,92.56$, and $86.66 \%$ in the $\mathrm{T} 1, \mathrm{~T} 2$, and $\mathrm{T} 3$ experimental periods, respectively. These data are apparently conflicting but can be explained because genotoxic damage can be repaired, and this repair may not have been apparent in the micronucleus assay because the assay only evaluated fixed damage in the cell genome (Salvadori et al., 2003; Mauro et al., 2013), which has a higher correlation with the genetic instability that can determine cancer development.

From among the various protocols proposed in the literature, the present study incorporated pretreatment, simultaneous treatment, and post-treatment groups in addition to a pre + continuous treatment group. Whereas the results in the simultaneous treatment group indicated both desmutagenic and bio-antimutagenic activities, those in the pretreatment and posttreatment protocols indicated activity that could be inferred as bio-antimutagenic (Ferguson, 1994; Flagg et al., 1995; De Flora and Ferguson, 2005; Oliveira et al., 2009, 2013; Pesarini et al., 2013). The results of the comet and micronucleus tests suggest that the tested food compound acted through both bio-antimutagenic and desmutagenic actions.

The potential carcinogenic and anticarcinogenic activities of the resistant starch were also evaluated within the context of the correlation between mutagenic and carcinogenic events, and resistant starch was verified to be noncarcinogenic and shown to lead to a significant reduction in pre-neoplastic lesions (aberrant crypt foci). Both the absolute values and the percentages of damage reduction showed that the activity in the simultaneous and post-treatment groups was statistically similar in terms of anticarcinogenicity. However, the best damage reduction percentages were observed in the pretreatment and pre + continuous treatment groups. The lowest crypts/foci ratio index was observed in the post-treatment group.

Because the largest anticarcinogenic effects were observed in the pretreatment and pre + continuous groups, we concluded that green banana flour may be an important food compound with cancer-preventing activity. Thus, including green banana flour in the daily diet of the general population could prevent genome damage associated with cancer development or even prevent cancer development. Even if cancer is already present in the body, the continual intake of this food supplement could be beneficial.

This conclusion encourages the use of supplements in organisms that already show the presence of cancer biomarkers. This suggestion is reinforced by the crypts/foci index in the post-treatment group, which was approximately 0.8 -fold lower than that observed in the positive control group. This value was significant and indicated that giving a resistant starch supplement to animals with already-initiated cancer could improve the prognosis; specifically, foci were less likely to develop into tumors. Thus, resistant starch could be sufficient to prevent full cancer development, which would correlate with improvements in the quality of life of the animals.

Given these findings, we observed no direct relationship between the time of resistant starch supplementation and its anticarcinogenic function. However, the results present strong evidence that this compound should be used continuously to address the following aspects of oncogenesis/carcinogenesis: 1) the prevention of genomic lesions that can induce cancer; 2 ) the prevention of intestinal mucosal changes (aberrant crypts) that are directly related to colorectal cancer development, and 3) a reduction in the crypts/foci ratio, which is related to a lower likelihood of intestinal mucosal lesions that develop into tumors. In particular, the crypts/foci ratio supports the inference of prognosis improvement in patients with existing polyps; for example, studies have concluded that in both animals and humans, the higher the crypts/foci ratio, the greater the progression of these lesions and the closer their proximities to established tumors (Cheng and Lai, 2003; Rudolph et al., 2005). 
Several factors can account for the anticarcinogenic activity of resistant starch and might have reduced the number of identified aberrant crypt foci. One factor is the decrease in serum glucose levels. Studies have established that rapid tumor proliferation depends on glucose availability (Roberfroid, 2005). Consumption of resistant starch reduces the energy capacity of cells in preneoplastic lesions. Consequently, resistant starch improves resistance to colonization, prevents bacterial translocation, and ultimately helps to improve the chemical and enzymatic functions that protect the gastrointestinal tract (Roberfroid, 2005). The increased motility of the large intestine reduces the time that stool remains in the colon and relieves constipation symptoms. Increased stool transit time and constipation are among the risk factors for colorectal cancer because fecal contact with the colon and rectal walls for prolonged periods of time increases the chances of developing this disease (Roberfroid, 2005; Mauro et al., 2013). Another activity of fiber is its adsorptive capacity. Ferguson (1994) reported that dietary fibers exhibit adsorptive capacity, acting as physical barriers that lead to the elimination through adsorption of certain chemical substances, including DMH, that could induce the initiation, promotion, or progression of carcinogenesis.

Because it cannot be digested in the small intestine, resistant starch is also a substrate for probiotic organism growth and thereby a potential prebiotic agent (Haralampu, 2000). The metabolism of this type of carbohydrate by microorganisms via fermentation produces short-chain fatty acids such as acetate, propionate, and butyrate; carbon and hydrogen gases; and, in some individuals, methane; it also decreases colon pH (Englyst et al., 1992). Most of these compounds prevent inflammatory diseases of the intestine and assist in the maintenance of intestinal epithelium integrity (Jenkins et al., 1998). A study by Englyst et al. (1992) demonstrated that 59\% of fermented starch is recovered as short-chain fatty acids at a molar ratio of 50:22:29 for acetate, propionate, and butyrate, respectively. Because butyrate is an important energy source for colon epithelial cells, its increased production can prevent colonic diseases (Englyst et al., 1992).

The other data obtained in this study provide evidence for weight reduction in the animals subjected to a resistant starch-containing diet, particularly for those in the pre + continuous group. Weight loss in these animals was likely due to various properties of resistant starch, including increased bowel motility, which reduces the time that fecal matter remains in the intestine and therefore decreases the absorption of food nutrients, especially fats. Fiber degradation in only this portion of the intestine reduces caloric value and decreases the glycemic rate (Roberfroid, 1993). The loss of calories also occurred because some of the energy was used to synthesize microbial biomass (Roberfroid, 1993). In addition, animals in this experimental group had the longest exposure to the resistant starch-rich diet, thus increasing the effectiveness of the various factors described above. No biologically relevant differences were observed with respect to the total and relative organ weights of animals, which suggests the absence of toxicity.

Given the relevant biological activities observed, green banana flour (resistant starch) appears to be a functional food. The concept of functional foods comes from the hypothesis that diet can control and modulate various organ functions and thus contribute to health maintenance and reduce the risk of disease development. Functional foods have biological markers for their functions in the body. These markers include, for example, increased numbers of non-pathogenic bacteria in the body, which aid in nutrient digestion and absorption, increased lactose tolerance, and immunostimulation (Borges, 2000). Other biological markers, particularly those that were evaluated in the present study of resistant starch, show antigenotoxic, antimutagenic, and anticarcinogenic functions. 
For a food to be classified as functional, it must have a metabolic or physiological effect that contributes to physical health and reduces the risk of chronic disease development, be part of the usual diet, have positive effects that can be obtained from non-toxic amounts and that persist even after the cessation of ingestion, and is not used to treat or cure diseases (Milner, 1999). All of these features could be attributed to green banana flour. The results of the present study show that resistant starch might act as an antigenotoxic, antimutagenic, and anticarcinogenic agent and is nontoxic to animals that consumed it in their diet. The results obtained from the experimental protocols suggest that this prebiotic might act via 2 methods of DNA damage prevention, desmutagenesis and bio-antimutagenesis. In carcinogenesis, resistant starch is believed to reduce the incidence of cancer biomarkers and improve disease prognosis by minimizing the number of biomarkers that develop into tumors. Thus, resistant starch has therapeutic properties that could be exploited in human dietary applications.

\section{ACKNOWLEDGMENTS}

We thank the Coca-Cola Company Brazil for awarding this research second place for the Pemberton Award (São Paulo/SP, Brazil 2013; 3rd edition), a company initiative directed toward professionals, research institutions, and universities in various areas of health and related fields. The main goal of the award is to stimulate scientific research on wellness approaches, such as the benefits of a balanced diet and physical exercise. We also thank the organizing committee of the National Biomedicine Meeting (Botucatu/SP, Brazil 2011; 14th edition) for the Edy de Lello Montenegro Award.

\section{REFERENCES}

Asp NG and Björck I (1992). Resistant starch. Trends Food Sci. Technol. 3: 111-114.

Bergmann MM, Bodzioch M, Bonet ML, Defoort C, et al. (2006). Bioethics in human nutrigenomics research: European Nutrigenomics Organisation workshop report. Br. J. Nutr. 95: 1024-1027.

Bird RP (1987). Observation and quantification of aberrant crypts in the murine colon treated with a colon carcinogen: preliminary findings. Cancer Lett. 37: 147-151.

Bolognani F, Rumney CJ, Pool-Zobel BL and Rowland IR (2001). Effect of lactobacilli, bifidobacteria and inulin on the formation of aberrant crypt foci in rats. Eur. J. Nutr. 40: 293-300.

Borges VC (2000). Alimentos Funcionais: Prebióticos, Probióticos, Fitoquímicos e Simbióticos. In: Nutrição Oral, Enteral e Parenteral na Prática Clínica (Waitzberg DL, ed.). Atheneu, São Paulo, 1495-1509.

Burns AJ and Rowland IR (2004). Antigenotoxicity of probiotics and prebiotics on faecal water-induced DNA damage in human colon adenocarcinoma cells. Mutat. Res. 551: 233-243.

Champ M and Faisant N (1996). Resistant starch: analytical and physiological aspects. Bol. SBCTA 30: 37-43.

Chao A, Thun MJ, Connell CJ, McCullough ML, et al. (2005). Meat consumption and risk of colorectal cancer. JAMA 293: 172-182.

Cheng L and Lai MD (2003). Aberrant crypt foci as microscopic precursors of colorectal cancer. World J. Gastroenterol. 9: 2642-2649.

Clark MJ, Robien K and Slavin JL (2012). Effect of prebiotics on biomarkers of colorectal cancer in humans: a systematic review. Nutr. Rev. 70: 436-443.

De Flora S and Ferguson LR (2005). Overview of mechanisms of cancer chemopreventive agents. Mutat. Res. 591: 8-15.

Englyst HN, Kingman SM and Cummings JH (1992). Classification and measurement of nutritionally important starch fractions. Eur. J. Clin. Nutr. 46 (Suppl 2): S33-S50.

Ferguson LR (1994). Antimutagens as cancer chemopreventive agents in the diet. Mutat. Res. 307: 395-410.

Flagg EW, Coates RJ and Greenberg RS (1995). Epidemiologic studies of antioxidants and cancer in humans. J. Am. Coll. Nutr. 14: 419-427.

Haralampu SG (2000). Resistant starch-a review of the physical properties and biological impact of RS3. Carbohydr. 
Polym. 41: 285-292.

Hayashi M, Morita T, Kodama Y, Sofuni T, et al. (1990). The micronucleus assay with mouse peripheral blood reticulocytes using acridine orange-coated slides. Mutat. Res. 245: 245-249.

Instituto Nacional do Câncer (2012). Estimativa 2012. Available at [http://portal.saude.sp.gov.br/resources/ses/perfil/ gestor/homepage/estimativas-de-incidencia-de-cancer-2012/estimativas_incidencia_cancer_2012.pdf]. Accessed September 25, 2014.

Instituto Nacional do Câncer (2014). Estimativa 2014. Available at [http://www.inca.gov.br/estimativa/2014/index. asp?ID=2]. Accessed September 25, 2014.

Jenkins DJ, Vuksan V, Kendall CW, Wursch P, et al. (1998). Physiological effects of resistant starches on fecal bulk, short chain fatty acids, blood lipids and glycemic index. J. Am. Coll. Nutr. 17: 609-616.

Juarez-Garcia E, Agama-Acevedo E, Sáyago-Ayerdi SG, Rodríguez-Ambriz SL, et al. (2006). Composition, digestibility and application in breadmaking of banana flour. Plant Foods Hum. Nutr. 61: 131-137.

Kobayashi H, Sugiyama C, Morikawa Y and Hayashi M (1995). A comparison between manual microscopic analysis and computerized image analysis in the single cell gel electrophoresis assay. MMS Commun. 3: 103-115.

Liu R and Xu G (2008). Effects of resistant starch on colonic preneoplastic aberrant crypt foci in rats. Food Chem. Toxicol. 46: 2672-2679.

Manoharan K and Banerjee MR (1985). beta-Carotene reduces sister chromatid exchanges induced by chemical carcinogens in mouse mammary cells in organ culture. Cell Biol. Int. Rep. 9: 783-789.

Mauro MO, Sartori D, Oliveira RJ, Ishii PL, et al. (2011). Activity of selenium on cell proliferation, cytotoxicity, and apoptosis and on the expression of CASP9, BCL-XL and APC in intestinal adenocarcinoma cells. Mutat. Res. 715: 7-12.

Mauro MO, Monreal MT, Silva MT, Pesarini JR, et al. (2013). Evaluation of the antimutagenic and anticarcinogenic effects of inulin in vivo. Genet. Mol. Res. 12: 2281-2293.

McBain AJ and MacFarlane GT (2001). Modulation of genotoxic enzyme activities by non-digestible oligosaccharide metabolism in in-vitro human gut bacterial ecosystems. J. Med. Microbiol. 50: 833-842.

Milner JA (1999). Functional foods and health promotion. J. Nutr. 129: 1395S-1397S.

Muir JG and O'Dea K (1992). Measurement of resistant starch: factors affecting the amount of starch escaping digestion in vitro. Am. J. Clin. Nutr. 56: 123-127.

Oliveira RJ, Baise E, Mauro MO, Pesarini JR, et al. (2009). Evaluation of chemopreventive activity of glutamine by the comet and the micronucleus assay in mice's peripheral blood. Environ. Toxicol. Pharmacol. 28: 120-124.

Oliveira RJ, Salles MJ, da Silva AF, Kanno TY, et al. (2013). In vivo evaluation of the antimutagenic and antigenotoxic effects of beta-glucan extracted from Saccharomyces cerevisiae in acute treatment with multiple doses. Genet. Mol. Biol. 36: 413-424.

Pesarini JR, Zaninetti PT, Mauro MO, Carreira CM, et al. (2013). Antimutagenic and anticarcinogenic effects of wheat bran in vivo. Genet. Mol. Res. 12: 1646-1659.

Roberfroid MB (1993). Dietary fiber, inulin, and oligofructose: a review comparing their physiological effects. Crit. Rev. Food Sci. Nutr. 33: 103-148.

Roberfroid MB (2005). Introducing inulin-type fructans. Br. J. Nutr. 93 (Suppl 1 1): S13-S25.

Rodrigues MA, Silva LA, Salvadori DM, de Camargo JL, et al. (2002). Aberrant crypt foci and colon cancer: comparison between a short- and medium-term bioassay for colon carcinogenesis using dimethylhydrazine in Wistar rats. Braz. J. Med. Biol. Res. 35: 351-355.

Rudolph RE, Dominitz JA, Lampe JW, Levy L, et al. (2005). Risk factors for colorectal cancer in relation to number and size of aberrant crypt foci in humans. Cancer Epidemiol. Biomarkers Prev. 14: 605-608.

Salvadori DMF, Ribeiro LR and Fenech M (2003). Teste do Micronúcleo em Células Humanas In Vitro. In: Mutagênese Ambiental (Ribeiro LR, Salvadori DMF and Marques EL, eds.). ULBRA, Canoas, 201-219.

Stevens RG, Swede H and Rosenberg DW (2007). Epidemiology of colonic aberrant crypt foci: review and analysis of existing studies. Cancer Lett. 252: 171-183.

Vogel EW (1982). Assessment of Chemically-Induced Genotoxic Events: Prospectives and Limitations. The Netherlands University Press, Leiden, 2-24. 